\title{
PENDIDIKAN KARAKTER BERBASIS KEARIFAN LOKAL: DALAM PERSPEKTIF KEILMUAN FISIKA
}

\author{
Jeffry Handhika \\ Program Studi Pendidikan Fisika FPMIPA \\ Institusi IKIP PGRI Madiun \\ Jl. Setiabudi No. 85 \\ Email : jeffry.handhika@yahoo.com
}

\begin{abstract}
Abstrak
Meningkatnya kekerasan dikalangan remaja, korupsi dan permasalahan moral lainnya merupakan masalah nasional yang harus segera diselesaikan. Salah satu cara yang dapat digunakan adalah menjaga sistem supaya berjalan ideal. Selain penegakan hukum, penanaman karakter berbasis kearifan lokal merupakan faktor penting yang perlu dijaga. Karakter berbasis kearifan lokal merupakan cikal bakal karakter bangsa. Bangsa yang besar adalah bangsa yang tidak kehilangan jati diri dan mampu menjaga sistem dengan baik. Pendidikan karakter, merupakan arti dari pendidikan itu sendiri. Pendidikan merupakan seluruh rangkaian aktivitas yang dilakukan pendidik untuk peserta didik terhadap semua aspek perkembangan potensi kecerdasan dan kepribadian (karakter baik) yang dilakukan secara kontinu untuk mencapai tujuan setinggi-tingginya. Dengan proses pendidikan yang baik, permasalahan moral di indonesia dapat diminimalisir, oleh karena itu implementasi pendidikan karakter terus dilakukan baik dalam kurikulum maupun secara teknis dalam SSP. Alternatif lain dapat dilakukan dengan memadukan keilmuan Fisika dalam hal ini konten materi dalam penanaman nilai karakter.
\end{abstract}

Kata kunci : Pendidikan Karakter, Kearifan lokal, Keilmuan Fisika

\section{Pendahuluan}

Meningkatnya kekerasan dikalangan remaja, pengunaan bahasa dan kata-kata yang memburuk, pengaruh peergroup yang kuat dalam tindak kekerasaan, meningkatnya prilaku yang merusak diri seperti penggunaan narkoba, alkohol, dan prilaku seks bebas, semakin kaburnya pedoman moral baik dan buruk, menurunya etos kerja, semakin rendahnya rasa hormat kepada orangtua dan guru, rendahnya rasa tanggung jawab individu dan warga negara, membudidayakan ketidakjujuran, adanya saling curiga dan kebencian antar sesama merupakan ciri-ciri bangsa yang akan mengalami kehancuran (Linckona:2004). Semua ciri-ciri yang diungkap diatas mengarah pada kondisi bangsa kita sekarang ini. Persoalan karakter di indonesia khususnya sebenarnya tidak terabaikan sepenuhnya. Bangsa indoneesia menjadikan pembangunan karakter sebagai cita-cita luhur dan jati diri bangsa indonesia.

Bahwa sesungguhnya kemerdekaan itu ialah hak segala bangsa dan oleh sebab itu, maka penjajahan diatas dunia harus dihapuskan karena tidak sesuai dengan perikemanusiaan dan perikeadilan.

Kutipan alinea pertama pembukaan UUD 1945 menunjukkan bahwa bangsa Indonesia sangat menjunjung tinggi prikemanusiaan dan prikeadilan, dua aspek ini akan bisa terwujud ketika masyarakat indonesia saling menghormati dan menghargai antar sesama maupun dengan bangsa lain. Kepedulian terhadap bangsa lain, masyarakat dan sesama juga sangat tegas termaktub dalam alenia ini.Kondisi yang kami paparkan diatas tidak hanya terjadi di Indonesia. Negara maju seperti amerika dan negara berkembang seperti cina juga mengalami kondisi yang sama.Amerika misalnya, dari hasil publikasi The Index of Leading Cultulal IndicatordalamLickona(2012):

antara tahun 1960-1990-an, penduduk meningkat $41 \%$, bruto produk domestik meningkat tiga kali lipat, total pengeluaran pemerintah di semua level meningkat lebih dari lima kali lipat. Namun selama periode yang sama, hampir setiap indikator stabilitas sosial dan kesehatan moral bergeser secara dramatis ke arah yang negatif. Kejahatan dengan kekerasan meningkat 500\%, kasus remaja bunuh diri meningkat tiga kali lipat, perceraian dua kali lipat (menjadi tertinggi di dunia), sekitar $40 \%$ anak-anak tidur dirumah dimana ayah mereka tidak tinggal disana, sebagian besar ayah yang bercerai tidak memberikan tunjangan pada anaknya, kelahiran oleh ibu yang tidak menikah meningkat lebih dari $400 \%$.

Data lain dalam kartu laporan tentang etika pemuda amerika 2002, yang diterbitkan oleh Institut Josephson dalam Lickona (2012):

Tiga dari empat siswa mengaku melakukan kecurangan pada ujian disekolah selama satu tahun terakhir, hampir empat dari sepuluh siswa mengatakan mereka telah mencuri sesuatu dari toko selama setahun terakhir, hampir empat dari sepuluh siswa mengatakan 
mereka"akan berbohong untuk mendapatkan Kondisi di China juga kurang lebih sama, sampai saat ini masih terdapat korupsi yang dilakukan oleh pemerintah daerah walaupun hukuman yang diberikan sudah ditegakkan. Kutipan berita dari http://www.antaranews.com sebagai berikut:

Zhou Zhenhong (56) mantan kepala Departemen Fron Persatuan Kerja (UFWD) di Provinsi uangdong mengaku menerima suap sebesar 24,6 juta yuan atau sekitar empat juta dolar (setara dengan 46,6 miliar rupiah) antara tahun 2002 hingga 2011, pengadilan tinggi di Henan, China tengah menyatakan. Ia dihukum mati dengan masa penangguhan dua tahun, bentuk hukuman yang biasanya akan diringankan menjadi hukuman seumur hidup. Zhou juga dinyatakan bersalah karena memiliki aset yang tidak bisa dijelaskan bernilai lebih dari 37 juta yuan atau sekitar 70 miliar rupiah.

Indonesia, Amerika dan Cina mengalami krisis moral yang sama. Kondisi ini tentunya sangat memprihatikan. Penelitian sederhana dilakukan oleh para peneliti untuk mengungkap karakter orang seluruh dunia dengan cara menyebar 1.100 dompet berisi $\$ 50$. Tujuannya untuk mengetahui berapa dompet yang dikembalikan. Hasil dari "The Wallet Test, Reader's Digest Desember 1995" dalam Thomas Lickona (2012) menyebutkan "56 persen dari dompet dikembalikan; 44 persen dibawa pergi. Norwegia dan Denmark mendapatkan penghargaan pertama, karena 100 persen dari dompet dikembalikan, empat negara kategori rendah Italia (35 persen dikemblikan), Swiss (35 persen), Hongkong (30\%), Meksiko (21 persen). Amerika (67 persen).

Dari hasil penelitian dan fenomena diatas, ternyata masalah karakter tidak hanya di Indonesia, negara maju maupun negara berkembang juga mengalami masalah yang sama. Krisis kararakter (moral) merupakan masalah bersama (nasional bahkan internasional) dan solusinya dapat dikaji dari berbagai sudut pandang sesuai dengan karakteristik masing-masing negara, maupun daearah.

\section{Teori}

\section{Pengertian Pendidikan}

Ki Hajar Dewantara (dalam Syamsul Kurniawan:2013) mengungkapkan bahwa "pendidikan sebagai tuntunan segala kekuatan kodrat yang ada pada anak agar mereka kelak menjadi manusia dan anggota masyarakat yang dapat mencapai keselamatan dan kebahagiaan yang setinggi-tingginya". Menurut Godfrey Thomson (dalam Tholib Khasan:2009), pendidikan adalah pengaruh lingkungan atas individu untuk menghasilkan perubahan-perubahan yang tetap (permanen) di dalam kebiasaan tingkah lakunya, pikiran dan sifatnya. Balitbang Kurikulum hasil pekerjaan yang bagus".

Kemendiknas (2010), "Pendidikan ialah usaha sadar dan sistematis dalam mengembangkan potensi murid". Potensi peserta didik tentunya tidak hanya potensi kognitif, namun karakter baik juga merupakan potensi yang harus dikembangkan. Dalam pasal 1 UU sistem pendidikan Nasional Nomor 20 Tahun 2003 dinyatakanbahwa "Pendidikan adalah usaha sadar dan terencana untuk mewujudkan suasana belajar dan proses pembelajaran agar peserta didik secara aktif mengembangkan potensi dirinya untuk memiliki kekuatan spiritual keagamaan, pengendalian diri, kepribadian, kecerdasan, akhlak mulia, serta keterampilan yang diperlukan dirinya, masyarakat, bangsa dan negara". Dari definisi yang diungkapkan diatas dapat disimpulkan bahwa pendidikan merupakan seluruh rangkaian aktivitas yang dilakukan pendidik untuk peserta didik terhadap semua aspek perkembangan potensi kecerdasan dan kepribadian (karakter baik) yang dilakukan secara kontinu untuk mencapai tujuan setinggi-tingginya.

\section{Pengertian Karakter}

Menurut Novak dalam (Lickona,2012) karakter merupakan "campuran kompatibel dari seluruh kebaikan yang diidentifikasi oleh tradisi religius, cerita sastra, kaum bijaksana, dan kumpulan orang berakal sehat yang ada dalam sejarah". Aristoteles dalam (Lickona,2012) juga mendefinisikan karakter baik sebagai kehidupan dengan melakukan tindakan-tindakan yang benar sehubungan dengan diri seseorang dan orang lain". Cheng, Chao-Shun (2007) berpendapat bahwa "Caracter:Internal cultivation and externally demonstrated behavior forms individual traits. An individual of character displays respectable traits and he/she is able to behave correctly and is a social model of morality. Individual character traits have been shaped by the selection of moralcognition, emotion, and love and are expressed in behavior"

Lebih spesifik lagi definisi karakter gini $\mathrm{Al}$ and Green, R.M (2013):

The word "character" comes from a Greek noun meaning "etching" or "engraving": charakt $\bar{e} r$ ( $\chi \alpha \rho \alpha \kappa \tau \eta \dot{\rho} \rho)$, itself derived from the verb charassein ("to engrave"). Originally charakt $\bar{e} r$ designated the marks impressed on a coin. Applied to human beings, charakt $\bar{e} r$ refers to the enduring marks or etched-in factors that have been impressed on a person' $s$ mind ( psuch $\bar{e}$, "soul”). These consist in the person's inborn talents as well as in the learned traits - those acquired through education and experience. These "engravings" set us apart, define us, and motivate our behavior.

Karakter secara kebahsaan ialah sifat-sifat kejiwaan, akhlak atau budi pekerti yang membedakan seseorang dari yang lain, tabiat atau watak 
(Departemen Pendidikan nasional,2008). Karakter merupakan watak, tabiat, akhlak atau kepribadian seseorang yang terbentuk dari hasil internalisasi berbagai kebijakan (virtues) yang diyakini dapat digunakan sebagai landasan untuk cara pandang, berpikir, bersikap dan bertindak (Kemendiknas Balitbang, 2010).

Dari definisi diatas dapat disimpulkan bahwa karakter merupakan watak, tabiat atau kepribadian seseorang yang melekat pada dirinya yang diperoleh dari interaksi kegiatan maupun proses alami yang digunakan sebagai landasan untuk cara pandang, berfikir maupun bertindak. Sebenarnya penafsiran arti kata karakter ini masih menyisakan perdebatan, yang nantinya akan mempengaruhi tujuan, pengembangan dan desain pendidikan karakter itu sendiri. Berdasarkan pendapat para ahli diatas ada dua cara pandang tentang definisi karakter, (1) karakter sebagai hasil, (2) karakter dipahami sebagai sebuah proses.

\section{Pendidikan Karakter}

Haedar Nasir (2013) mengungkapkan bahwa "Pendidikan bukan hanya melahirkan manusia cerdas secara intelektual dan profesional, tetapi lemah spiritual, moral, emosional, estetika, dan fungsi sosialnya layaknya robot". Dalam UU No. 2 Tahun 1989 Tentang sistem Pendidikan Nasional, "Pendidikan adalah usaha sadar untuk menyiapkan peserta didik melalui kegiatan bimbingan, penagajaran atau latihan bagi peranannya di masa datang". Dalam pasal 3 UU sistem pendidikan Nasional Nomor 20 Tahun 2003 dinyatakan:

Pendidikan nasional berfungsi
mengembangkan dan membentuk watak serta peradaban bangsa yang bermartabat dalam rangka mencerdaskan kehidupan bangsa, bertujuan untuk berkembangnya potensi peserta didik agar menjadi manusia yang beriman dan bertaqwa kepada tuhan Yang Maha Esa, berakhlak mulia, sehat, berilmu, cakap, kreatif, mandiri, dan menjadi warga negara yang demokratis dan tanggung jawab".

Amanat UU tersebut sangat jelas bahwa tujuan pendidikan tidak hanya berorentasi pada aspek kecerdasan dan keilmuan, tetapi juga upaya mendidik karakter baik (berahlak mulia, cakap, kratif, mandiri), sehingga dapat membentuk karakter bangsa yang demokratis dan bertanggungjawab. Haedar Nasir (2013) menyatakan bahwa "pendidikan adalah suatu usaha sadar dan sistematis dalam mengembangkan potensi peserta didik".

Pendidikan dan karakter merupakan satu rangkaian karena saling berkaitan. Dari pemaparan diatas, tujuan pendididikan adalah membentuk karakter baik. David Light Shields (2011) menyatakan" We propose character as the aim of education".Lickona (2012) Menyatakan bahwa "Pada kenyataanya, pendidikan moral ternyata sudah seumur pendidikan sendiri”. Lebih lanjut Lickona mengungkapkan bahwa "berdasarkan penelitian sejarah dari seluruh negara yang ada di dunia ini, pada dasarnya pendidikan memiliki dua tujuan, yaitu membimbing para generasi muda untuk menjadi cerdas dan memiliki prilaku berbudi". Dari ungkapan para ahli dapat ditarik kesimpulan bahwa pendidikan memiliki tujuan untuk membentuk karakter yang baik, pendidikan karakter ada, karena tujuan pendidikan itu sendiri. Martin Luther King Jr. Dalam pidatonya di Morehouse College tahun 1948 menyatakan: "We Must remember that intelligence is not enough. Intelligence plus character-that is the goal of true education".

Doni Koesoema A. (2010) memberikan pengertian rinci mengenai pendidikan karakter. "Pendidikan karakter berasal dari kata pendidikan dan karakter. Pendidikan ialah proses internalisasi budaya ke dalam diri individu dan masyarakat menjadi beradab, sedangkan karakter memiliki persamaan makna dengan kepribadian". Lebih lanjut Doni Koesoema A mengungkapkan bahwa "kepribadian merupakan sifat khas seseorang yang bersumber dari bentukan-bentukan yang diterima lingkungan".

Winton (2008) mengungkapkan bahwa "Character education is the intentional effort by educators to teach values to students. Character initiatives have been reintroduced in public schools in response to concerns about moral decline, school safety, social cohesion, civic engagement, and academic achievement". Cheng, Chao-Shun (2007) mendefinisikan "character education refers to a teaching activity that helps students to acquire a "universalvalue," "core value" and "moral education" and enables students to think and act within a moralscope". Senada dengan pernyataan saya tentang definisi karakter, tujuan pendidikan karakter juga dapat mengalami kontroversi. Belum ada kejelasan tujuan pendidikan karakter ini mau diarahkan kemana. Pendidikan karakter dapat diarahkan (1) pada pengembangan kepribadian, (2) penanaman nilai-nilai tertentu, (3) memperbaiki nilai-nilai moral (4) berfokus pada pendidikan rohani (agama). Pada pembahasan selanjutnya akan difokuskan pada penanaman nilai-nilai tertentu

\section{Nilai Karakter Dasar (moral) pada Pendidikan Karakter}

Penyelenggaraan pendidikan karakter di sekolah atau dikampus harus berpijak kepada nilainilai karakter dasar, yang selanjutnya dikembangkan menjadi nilai-nilai yang lebih banyak atau lebih tinggi (yang bersifat tidak absolut atau bersifat relatif) sesuai dengankebutuhan, kondisi, dan lingkungan sekolah atau kampus itu sendiriAchmad Husen dkk., (2010). T. Ramli (2003) dalam (Achmad Husen dkk., 2010) mengemukakan bahwa "pendidikan karakter memiliki esensi dan makna yang sama dengan pendidikan moral dan pendidikan 
akhlak. Tujuannya adalah membentuk pribadi anak, supaya menjadi manusia yang baik, warga sosial tertentu, yang banyak dipengaruhi oleh budaya masyarakat dan bangsanya. Oleh karena itu, hakikat dari pendidikan karakter dalam konteks pendidikan di Indonesia adalah pedidikan nilai, yakni pendidikan nilai-nilai luhur yang bersumber dari budaya bangsa Indonesia sendiri, dalam rangka membina kepribadian generasi muda".

Bentuk nilai yang sebaiknya diajarkan disekolah adalah kejujuran, keadilan, toleransi, kebijaksanaan, disiplin diri, tolong-menolong, peduli sesama, kerja sama, keberanian, dan sikap demokratis. Nilai-nilai khusus tersebut merupakan bentuk dari rasa hormat dan atau tanggung jawab ataupun sebagai media pendukung untuk bersikap hormat dan tanggung-jawab (Lickona,2012).

\section{Kearifan Lokal}

Local wisdom refers to the knowledge that comes from the community's experiences and the accumulation of local knowledge (Kamonthip and Kongprasertamorn:2007). Wagiran (2012) menyatakan "Kearifan lokal merupakan sebuah budaya kontekstual. Kearifan selalu bersumber dari hidup manusia. Ketika hidup itu berubah, kearifan lokal pun akan berubah pula. Lebih lanjut Wagiran mengungkapkan bahwa "Paling tidak kearifan lokal dapat muncul pada (a) pemikiran, (b) sikap, dan (c) prilaku". Nurma (2007) mengungkapkan bahwa "Kearifan lokal atau yang kerap disebut sebagai local wisdom dimaknai sebagai usaha manusia baik dari suku, budaya maupun agama. Konsekwensinya kearifan lokal pada masing-masing daerah berbeda, tergantung pada perkembangan masyarakatnya. local wisdom of the depth of the Indonesian culture is a compilation of ethnic cultures, a process expressed in the lives of a people through learning practices. In another case, the local wisdom is a system of meanings of the communal societies instead of the individuals, and in the later expansion, it is a form of social process rather than an individual one. (Meliono:2011)

\section{KAJIAN}

\section{Kegunaan Karakter Berbasis Kearifan Lokal}

"Bila suatu negara dikelola berdasarkan hukum, hukuman bisa mencegah rakyat melanggar hukum. Oleh karena itu, rakyat hanya takut melanggar hukum atau berusaha menghindar dari jeratan hukum". (Andri Wang: 2013). Dari kutipan kalimat diatas dapat kita pahami bahwa sistem memang dapat dijaga dengan menegakkan hukum, akan tetapi penegakkan hukum hanya akan membuat rakyat melanggar hukum dan atau menghindari hukum, akan berbeda jika sistem dibentuk dari kesadaran, dalam arti rakyat merasa malu dan berdosa ketika melanggar hukum. Peran utama dari karakter berbasis kearifan lokal adalah dengan menggunakan akal budinya untuk bertindak dan bersikap terhadap sesuatu, objek atau peristiwa yang terjadi dalam ruang tertentu". Dari berbagai pendapat diatas dapat disimpulkan bahwa kearifan lokal (local Wisdom) merupakan pengetahuan yang lahir dari pengalaman komunitas dan akumulasi pengetahuan setempat yang dapat muncul dari pemikiran, sikap dan prilaku. Phongphit dan Nantasuwan dalam (Kamonthip and Kongprasertamorn:2007) mensyaratkan kearifan lokal menjadi "(1) local wisdom must incorporate knowledge of virtue that teaches people about ethics and moral values; (2) local wisdom must teach people to love nature, not to destroy it; and (3) local wisdom must come from the older members of the community. mereka juga menjelaskan bahwa "local wisdom is presented in many forms, through people's thoughts, occupations, ways of living, and social values".

Cahyanto SS et al (2012) mempertegas pendapat para pakar diatas dengan menyatakan "Kearifan lokal sama sekali tidak bisa diperoleh melalui suatu pendidikan formal dan informal tetapi hanya bisa dipahami dari suatu pengalaman yang panjang melalui pengamatan langsung. Kearifan lokal lahir dari learning by experience yang tetap dipertahankan dan diturunkan dari generasi ke generasi”. Indonesia merupakan negara yang heterogen,

menjaga sistem keteraturan dalam arti menciptakan keseimbangan antara kehidupan sosial, budaya dan juga kelestarian alam.

Pengkajian Keilmuan Fisika Tentang Pentingnya Karakter Berbasis Kearifan Lokal Dalam Menjaga Kesetabilan Sistem

Dalam konteks keilmuan fisika, dalam hal ini termodinamika, dinyatakan bahwa " sistem berada dalam kesetimbangan termodinamik akan terjadi jika tiga syarat terpenuhi, yaitu kesetimbangan termal, kesetimbangan mekanik dan kesetimbangan kimia”. Sama halnya dengan negara, menurut pendapat subjektif saya, dalam menjaga sistem tidak hanya penegakan hukum yang dibutuhkan, akan tetapi penyadaran masyarakat akan "budaya malu" perlu ditekankan. Jika keduanya berlangsung sinergis, maka kesetabilan sistem dapat terjaga dalam waktu yang lama. Kesetabilan sistem hanya akan tercapai dalam sistem yang konservatif (berada pada kerangka inesia). Jika ada transfer energi atau gaya luar yang mempengaruhi, maka kesetabilan sistem akan terganggu. Sistem harus dibangun secara kontinu, karena dalam fungsi sosial, manusia berkembang yang menyebabkan budaya berkembang. Perkembangan budaya melahirkan faktor eksternal baru yang dapat mengganggu kesetabilan sistem. Sistem yang lebih konprehensif 
perlu dibangun untuk menjaga kesetabilan yang mendekati ideal.

Manusia merupakan sistem yang komplek. Masyarakat dan negara merupakan gabungan dari sistem yang komplek. Di dalam manusia dan kehidupan masyarakat melekat nilai (karakter) dan hukum. Sisten nilai berkembang seiring perkembangan manusia, begitu juga hukum. Keseimbangan sistem akan tercapai jika sistem yang dibuat juga berkembang. Persamaan gas ideal memberikan $P V=n R T$, dengan memasukkan dan menyederhanakannya nilai dan konstantanya kita peroleh $P V=T$. Sistem ideal ini dapat kita analogikan dengan fenomena sosial dan menjadikan fungsinya lebih komplek dengan menambahkan faktor yang lebih banyak pada fungsi koordinat termodinamik, misalnya $P_{(n, m, o \ldots)} V_{(n, m, o \ldots)}=$ $T_{(n, m, o \ldots)}$. Selain menggunakan sistem kesetimbangan termodinamik, hukum kekekalan energi, kekekalan momentum dan persamaan fisika lainnya dapat kita gunakan untuk melakukan analisa sosial, dengan syarat dalam sistem yang konservatif.

\section{Implikasi Pendidikan Karakter Dalam} Pendidikan Fisika (IPA) Dalam Kurikulum

Implementasi pendidikan karakter dalam pendidikan IPA mengharuskan pendidikan karakter terintegrasi dengan kurikulum, lebih dalam lagi merambah ke seluruh kehidupan sekolah (Doni Koesoma A, 2012). Konsekwensinya, proses pembelajaran didalam kelas dirancang dengan tujuan memberikan tantangan pengembangan ilmu pengetahuan bagi setiap siswa, menghargai keunikan setiap pembelajar, dan membantu mengembangkan karakter mereka sebagai pembelajar. Dalam pendidikan IPA terdapat istilah sikap ilmiah yang memiliki sinergitas dengan unsur nilai pada karakter. Dalam proses integrasi pendidikan IPA dalam SSP (Subject Spesific Pedagogy) (perangkat pembelajaran) telah dilakukan dan disosialisasikan dan dilaksanakan. Masalah yang paling besar tampak pada sistem evaluasi nilai karakter itu sendiri akibat konsekuensi dari definisi karakter yang berbeda. Perbedaan cara pandang ini tidak perlu dijadikan jurang pemisah dalam proses integrasi pendidikan karakter, karena pada hakekatnya semua memiliki tujuan yang baik. Im Fitri Yuliawati,(2010) dalam Damiyati Zuchdi (2013) menggunakan istilah "meningkatkan karakter dalam penilaiannya. J. Handhika (2010) menggunakan istilah "penumbuhan karakter" dalam penelitiannya. Iplikasi lain dari pendidikan karakter dalam pendidikan IPA adalah pelaksanaan pengajaran. Starategi, maupun metode pembelajaran yang digunakan guru/dosen harus melibatkan siswa. Secara tidak langsung penggunaan metode ceramah murni tidak relevan, karena aktivitas yang tampak (karakter) tidak dapat secara jelas.

\section{Memadukan Karakter Dalam Keilmuan Fisika (Sebuah Alternatif Pembelajaran)}

Implementasi pendidikan karakter di pendidikan IPA dalam pelaksanaanya sebagian masih dilakukan secara administratif, perkutat pada pengembangan SSP tanpa mengetahui bagaimana cara mengimplementasikanya. Praktisi pendidikan cenderung menempelkan unsur nilai karakter dalam proses penilaian. Phongphit and Nantasuwan dalam (Kamonthip and Kongprasertamorn:2007) berpendapat bahwa "The problem is that local wisdom usually is not officially published and promoted. As a consequence, it is difficult for the public to learn about and use this kind of knowledge". Dalam makalah ini saya mencoba untuk memberikan alternatif lain, dengan memasukan filosofi persamaan fisika dalam mengajarkan nilai karakter, baik karakter yang secara umum maupun yang bermuatan kearifan lokal.

\section{Penjelasan Korupsi}

Korupsi secara ideal tejadi ketika perencanaan tidak sesuai dengan pelaksanaan. Untuk menjelaskan korupsi ini kita bisa menggunakan persamaan fisika dalam sistem konservatif. Misalnya: hukum snelius memberikan:

$$
\frac{\sin \theta_{2}}{\sin \theta_{1}}=\frac{v_{2}}{v_{1}}
$$

Jika persamaan diatas tidak terpenuhi maka dapat disimpulkan terjadi korupsi. Mari kita renungkan pertanyaan berikut: Jika $\theta_{1}=\theta_{2}$ apakah terjadi korupsi?

Wagiran mengungkapkan bahwa "Paling tidak kearifan lokal dapat muncul pada (a) pemikiran, (b) sikap, dan (c) prilaku”. Dalam falsafah jawa terdapat istilah Neng, ning, nung, nang, yang memiliki arti substansial manusia ideal/menang adalah manusia yang dapat mengendalikan tiga fungsi, hawa nafsu duniawi, batin senantiasa tenang, dan ciptanya harus terpusat pada satu tujuan. Konten dalam materi termodinamika berpotensi untuk mengajarkan filosofi ini.

Meliono (2011) memberikan symbol of culture yang merupakan basic element dari local wisdom. Didalamnya terdapat local miyths, ritual, art, literary, architechture dan sebagainya. Seni dan literatur dalam budaya jawa mengingatkan kita pada tokoh wayang sengkuni. Sengkuni adalah tokoh pewayangan yang dapat merusak kesetabilan sistem. Perang baratayuda merupakan salah satu mahakarya lidah ular sengkuni. Istilah lidah ular saya ambil dari novel suwito sarjono yang berjudul musnahnya sengkuni. Sengkuni ini dapat kita identikkan dengan gaya luar yang mempengaruhi sistem. Ketika sengkuni (gaya luar) mempengaruhi maka sistem tidak ideal lagi. Untuk mengidealkan sistem, dapat dilakukan dengan mengabaikan sengkuni atau memperluas cara pandang. Kearifan negara lain 
Jeffry Handhika, Pendidikan Karakter Berbasis...

(cina) dapat dilihat pada simbol yin dan yang berikut yang saya ambil dari buku tao of physics karya

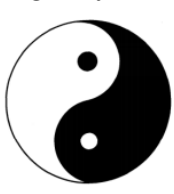

In the Chinese view, all manifestations of the Tao are generated by the dynamic interplay of these two polar forces.

This idea is very old and many generations worked on the symbolism of the archetypal pair yin and yang until it became the fundamental concept of Chinese thought. The original meaning of the words yin and yang was that of the shady and sunny sides of a mountain, a meaning which gives a good idea of the relativity of the two concepts: That which lets now the dark, now the light appear is Tao.g From the very early times, the two archetypal poles of nature were represented not only by bright and dark, but also by male and female, firm and yielding, above and below.

Penjelasan lebih lengkap dan mendalam dapat dibaca dalam buku Tao of Physics.

\section{Kesimpulan}

1. Pendidikan karakter sangat penting dan harus segera diterapkan secara menyeluruh baik di lingkungan keluarga, masyarakat, bangsa dan negara.

2. Pendidikan karakter yang berbasis kearifan lokal berpotensi menjadi karakter bangsa dan jati diri bangsa.

3. Implementasi pendidikan karakter di pendidikan IPA (Fisika) Berimplikasi positif terhadap pembelajaran, walaupun pada pelaksanaanya perlu ada pengkajian secara mendalam, bahkan ada yang hanya secara administratif.

4. Memadukan Karakter dengan konten Keilmuan Fisika berpotensi diterapkan dalam pembelajaran.

Output dari pendidikan karakter itu sendiri akan terlihat pada jangka panjang (generasi muda Indonesia berikutnya).

\section{Daftar Rujukan}

Achmad Husen dkk. 2010. Model Pendidikan Karakter Bangsa Sebuah pendekatan Monolitik di Universitas Negeri Jakarta. UNJ

Cahyanto SS et al. 2012. Penguatan Kearifan Lokal Sebagai Solusi Permasalahan Ketahanan
(Capra:1975).

Pangan Nasional. Procceding the $4{ }^{\text {th }}$.International Conference of Indonesian Studies: "Unity, Deversity and Future".

Capra F. 1975. THE TAO OF PHYSICS. An Exploration of the Parallels Between Modern Physics and Eastern Mysticism. Shambhala Publications, Inc. 1123 Spruce Street Boulder, Colorado 80302. ISBN: o-87773-077-6 (cloth)

Cheng, Chao-Shun. 2007.Character Education and Character-trait Development. Enrichment for College Students. Paper presented at the 2007 seminar of Kao Yuan University for General Educationat Kao Yuan UniversityKaohsiung County, ROC

Damiyati Zuchdi, dkk. 2013. Model Pendidikan Karakter Terintegrasi dalam Pembelajaran dan Pengembangan Kultur Sekolah.Yogyakarta. Multi Pressindo. ISBN No. 978-60218309-6-3

David Light. Kappan. 2011.kappanmagazine.org. V92 N8

Departemen Pendidikan dan Kebudayaan.2008. Kamus Besar Bahasa Indonesia.jakarta. Balai Pustaka.

Doni Koesoema A. Pendidikan Karakter utuh dan Menyeluruh. 2012. Yogyakarta. Kanisius. ISBN 978-979-21-3331-8

Gini, Al and Green, R.M. 2013. Ten Virtues of Outstanding Leaders: Leadership and Character. John Wiley \& Sons, Inc. ISBN 978-0-47067231-0. UK

Haedar Nashir.2013. Pendidikan Karakter Berbasis Agama dan Budaya.Yogyakarta. Multi 
Presindo. ISBN 978-902-175020-0

http://www.antaranews.com/berita/421538/peja bat-china-dihukum-mati-akibat-kasus-korupsi.

J. Handhika.2010. UpayaPenumbuhan karakter Positif Mahasiswa Melalui Lesson Study. Kridha Rakyat.

J. Handhika.2010. Upaya Peningkatan aktivitas Belajar dan pembentukan karakter mahasiswa melalui pembelajaran berbasis Proyek. Prosseding Seminar Nasional LS IV. UM Malang. ISBN 978-60297895-5-3

Kamonthip, Kongprasertamorn.2007. local wisdom, environmental protection and community development: the clam farmers in tambon bangkhunsai, phetchaburi province, thailand. MANUSYA: Journal of Humanities 10.1

Kementrian Pendidikan Nasional Badan Penelitian Pengembangan Pusat Kurikulum. Bahan Pelatihan: Pengembangan Pendidikan Budaya dan Karakter Bangsa, Jakarta. Kemendiknas. 2010

Mahbubi M. 2012. Implementasi Aswaja Sebagai Nilai Pendidikan Karakter. Pustaka Ilmu Jogjakarta. ISBN 978-60219212-7-2

Meliono I. 2012. Understanding the Nusantara Thought and Local Wisdom as an Aspect of the Indonesian Education.TAWARIKH:Internati onal Journal for Historical Studies, 2(2)

Nurma Ali Ridwan.2007. Landasan Keilmuan Kearifan Lokal. Ibda', Vol. 5, No. 1, Jan-Jun, 2007, h. 27-38.

Pembukaan UUD 1945. Pemerintah RI
Lickona T. 2012. Character Matters (Persoalan karakter): Bagaimana Membantu Anak Mengembangkan Penilaian yang baik, integritas, dan kebijakan penting lainnya (terjemahan).Jakarta. PT. Bumi Aksara. ISBN 978-602-217-2772

Lickona T. 2012. Educating for Character (Mendidik untuk membentuk karakter) Bagaimana sekolah dapat mengerjakan sikap hormat dan tanggung jawab (terjemahan).Jakarta. PT. Bumi Aksara. ISBN 978-602-217-2581

Sarjono S. 2013. Musnahnya Sengkuni.Diva Press.

Syamsul Kurniawan. 2013. Pendidikan Krakter: Konsep dan Implementasinya Secara Terpadu di Lingkungan Keluarga, Sekolah, Perguruan Tinggi dan Masyarakat. Yogyakarta. ARRUZZ Media. ISBN 978-6027874-48-0.

Tholib Kasan.2009. Dasar-Dasar Pendidikan. Jakarta Timur. Studia Press. ISBN 978-979-376-003-6

Undang-Undang Nomor 20 Tahun 2013. Sistem Pendidikan Nasional. Pemerintah RI

Undang-Undang Nomor 2 Tahun 1989. Sistem Pendidikan Nasional. Pemerintah RI

Wagiran.2012. Pengembangan karakter Berbasis Kearifan Lokal Hamemayu Hayuning Bawana. Jurnal Pendidikan Karakter. Tahun II No. 3

Winton, S. 2008. The appeal(s) of character education in threatening times: Caring and critical democratic responses. Comparative Education. 44(3), 3-5-316. 
Jeffry Handhika, Pendidikan Karakter Berbasis... 